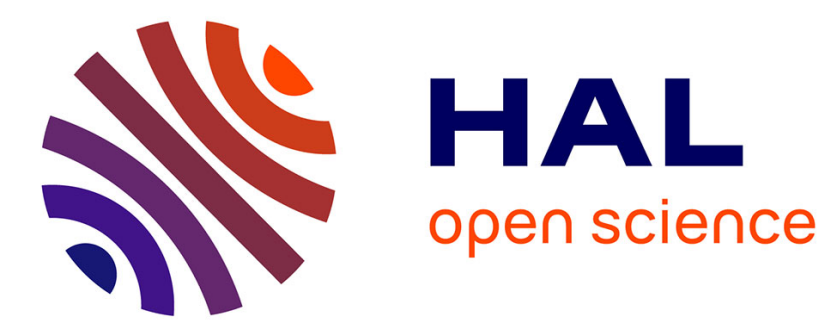

\title{
3D AFM Characterization of the Edge Roughness of Silicon High Q Resonators
}

P. Schiavone, M. Martin, P. Alipour, A.A Eftekhar, S. Yegnanarayanan, A. Adibi

\section{> To cite this version:}

P. Schiavone, M. Martin, P. Alipour, A.A Eftekhar, S. Yegnanarayanan, et al.. 3D AFM Characterization of the Edge Roughness of Silicon High Q Resonators. Conference on Lasers and Electro-Optics 2010, May 2010, San Jose (CA), United States. hal-00462233

\section{HAL Id: hal-00462233 https://hal.science/hal-00462233}

Submitted on 8 Mar 2010

HAL is a multi-disciplinary open access archive for the deposit and dissemination of scientific research documents, whether they are published or not. The documents may come from teaching and research institutions in France or abroad, or from public or private research centers.
L'archive ouverte pluridisciplinaire HAL, est destinée au dépôt et à la diffusion de documents scientifiques de niveau recherche, publiés ou non, émanant des établissements d'enseignement et de recherche français ou étrangers, des laboratoires publics ou privés. 


\title{
3D AFM Characterization of the Edge Roughness of Silicon High Q Resonators
}

\author{
P. Schiavone ${ }^{1,2}$, M. Martin'2, P. Alipour ${ }^{3}$, A. Eftekhar ${ }^{3}$, S. Yegnanarayanan ${ }^{3}$ and A. Adibi ${ }^{3}$ \\ ${ }^{I}$ UMI 2958 Georgia Tech-CNRS, Georgia Institute of Technology, 777 Atlantic Dr., Atlanta (GA) 30332, USA \\ ${ }^{2}$ Laboratoire des Technologies de la Microélectronique CNRS, 17, rue des martyrs, 38054 Grenoble, France \\ ${ }^{3}$ School of Electrical and Computer Engineering, Georgia Institute of Technology, 777 Atlantic Drive NW, Atlanta, GA 30332, USA \\ corresponding author : patrick.schiavone@gatech.edu
}

\begin{abstract}
Nanophotonic resonators are very sensitive to sidewall roughness. We investigate in detail the sidewall roughness, correlation length and fractal roughness exponent for high Q silicon resonators using a 3D AFM

(C)2010 Optical Society of America

OCIS codes: (130.3120) Integrated Optics devices; (120.0120) Instrumentation, measurement, and metrology
\end{abstract}

\section{Introduction}

Silicon-on-insulator (SOI) is a promising platform for realization of dense photonic integration. The large refractive index contrast in SOI entails that a strong electric filed is available close to the edge of the SOI waveguide and this makes SOI-based nanophotonic devices highly sensitive to the surface quality [1]. Yet, due to the lithography and etching process the Si photonic devices suffer from sidewall roughness. Such edge roughness could introduce both scattering losses as well as strong mode-splitting in high Q Si microresonators [2]. Hence, for Si photonic integrated circuit designs, it is critical to have a detailed measurement of the surface quality of nanophotonic devices. However, to our knowledge no such detailed sidewall roughness data is available and most results are extracted from SEM images which do not offer full reliability. In this work, we employ a 3D atomic force microscopy (AFM) technique to directly quantify the surface quality and estimate the relevant statistical properties of the sidewall surface for high Q Si microdisk resonators.

\section{Experimental procedure}

For this study our reference tool is the CD-AFM Dimension X3D from Veeco instruments. In contrast to other standard Atomic Force Microscopes (AFM), this equipment enables high resolution metrology in all axes [3]. Because of the flared tip used as well as because of the very specific feedback control of the tip, this instrument allows profiling vertical and even slightly reentrant sidewalls. This tool is invaluable in the characterization of the linewidth roughness in semiconductor manufacturing [4]. The roughness data measured from the 3D AFM have proved to be more reliable than the one from SEM data.

Figure 1 illustrates an experimental plot of one of the 3D AFM measurement of a resonator edge. The quantification of the roughness is performed using a fractal analysis [5]. The spatial roughness parameters are more reliably extracted from the height-height correlation function $G(r)$ defined as:

$$
G(m d)=\left[\frac{1}{N-m} \sum_{i=1}^{N-m}\left(\delta_{i+m}-\delta_{i}\right)^{2}\right]^{1 / 2} \quad \text { with } r=m d, d \text { being the sampling distance and } N \text { the number of samples }
$$

An example of an experimental height -height correlation of a roughness taken at a specific height is shown in Figure 2. The roughness $\sigma$ is extracted from the flat, long range part of the correlation curve which flattens out at a value of $\sqrt{2} \sigma$. The lower range can be approximated by a power law $\mathrm{r}^{\alpha}$ where $\alpha$ is the fractal roughness exponent. The correlation length $\xi$ is found from the point such as $G(\xi)=\sqrt{1-1 / e} \sqrt{2} \sigma$. The roughness can also be extracted in the usual way as the standard deviation of the rough spatial data. In the following section, this value is reported in addition to the one extracted from the height-height correlation curve.

We characterized 8 different microdisk resonators fabricated on the same SOI wafer, using a fabrication process that typically provides an ultra high Q (i.e., greater than 1 million for $10 \mu \mathrm{m}$ radius microdisks). The surface roughness of the developed e-beam resist mask (HSQ) sidewalls after e-beam lithography and the silicon sidewalls after the final silicon etch step were measured. Several AFM tips $(16 \mathrm{~nm}$ and $65 \mathrm{~nm})$ were used. For a given edge, 
several hundreds of scans are performed in a direction roughly perpendicular to the disk edge. The typical edge distance scanned is $2 \mu \mathrm{m}$ (the sampling distance being $7.8 \mathrm{~nm}$ and $10 \mathrm{~nm}$ for the sharp and large tip respectively). We observed almost no artifact caused by the tip on the extracted parameters.

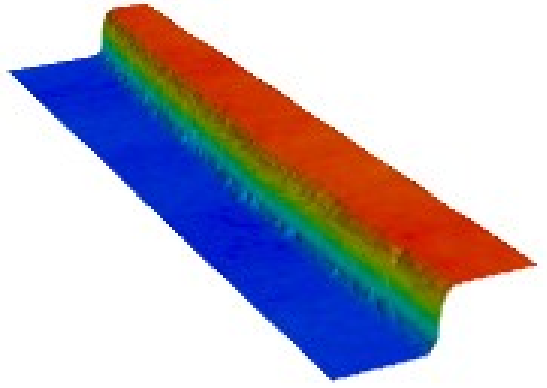

Figure 1: 3D AFM measurement of a disk resonator edge

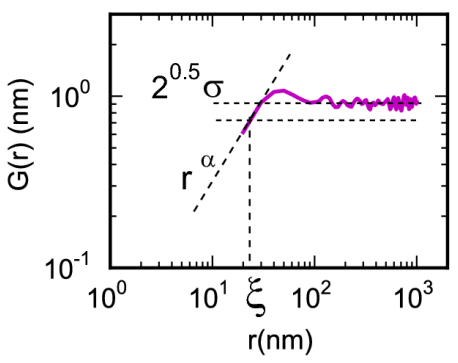

Figure 2: Height-height correlation function computed from real data. The roughness parameters $\alpha$ (fractal exponent), $\sigma$ (RMS roughness), $\xi$ (correlation length) are illustrated in the graph

\section{Results}

The results for 8 microdisk resonators measured after the etch step are summarized in Figure 3. One can observe that the roughness (Figure 3(a)) extracted from the spatial data (red bars) and from the correlation function (blue bars) match very well. The average edge roughness is $0.8 \mathrm{~nm}$ which is very low compared to typical values found in the CMOS manufacturing. The error bars reported on each bar of the bar plots are the standard deviation of the considered value measured at a different heights of the edge. The average correlation length is found to be $29.6 \mathrm{~nm}$ and the average roughness exponent is 0.94 . Note that the dispersion on the eight disks is rather small.

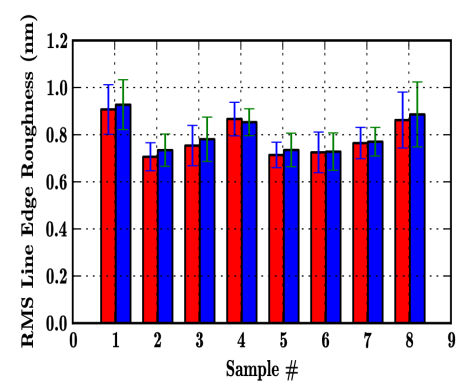

(a)

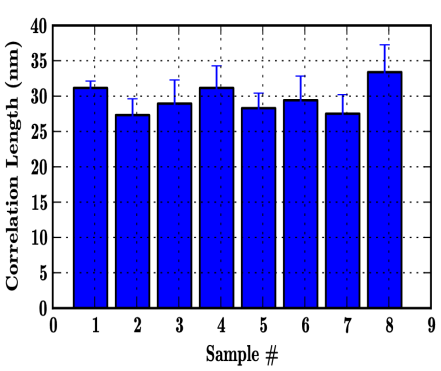

(b)

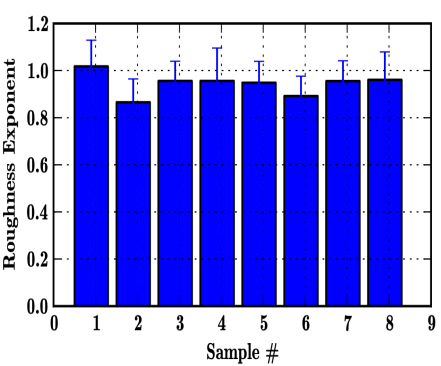

(c)

Figure 3: Bar plots of the extracted parameters on the eight disk resonators. (a) line edge roughness $\sigma$ extracted from the spatial data 'lefthand bars) and height-height correlation function (right-hand bars). (b) correlation length. $\xi$ (c) fractal roughness exponent $\alpha$

We observed that with the specific process used here, the roughness after the etch step is slightly reduced as compared to the roughness after the lithography $(0.95 \mathrm{~nm}$ vs $1.2 \mathrm{~nm})$ whereas the correlation length is almost unchanged. More detailed comparison between the roughness measurement and the optical response of the resonators will be shown at the conference

\section{References}

[1] Grillot, F., Vivien, L., Laval, S., Pascal, D. and Cassan, E., "Size influence on the propagation loss induced by sidewall roughness in ultrasmall SOI waveguides", IEEE Photonics Technology Letters 16(7), 1661-1663 (2004).

[2] Borselli, M., Srinivasan, K., Barclay, P. E. and Painter, O., "Rayleigh scattering, mode coupling, and optical loss in silicon microdisks.", Applied Physics Letters 85(17), 3693-3695 (2004).

[3] Martin, Y. and Wickramasinghe, H. K., "Method for imaging sidewalls by atomic force microscopy", Appl. Phys. Lett. 64(19), 2498-2500 (1994).

[4] Foucher, J., "From CD to 3D sidewall roughness analysis with 3D CD-AFM", Proc. SPIE 5752(1), 966-976 (2005).

[5] Constantoudis, V., Patsis, G. P., Tserepi, A. and Gogolides, E., "Quantification of line-edge roughness of photoresists. II. Scaling and fractal analysis and the best roughness descriptors", Journal of Vacuum Science \& Technology B, 21(3), 1019-1026 (2003). 